The state of change and almost constant

uncertainty may well be having an effect

on the self-esteem of the profession.

\title{
Which road should I take?
}

Recently the BBC aired a series of television programmes about the development of a group of babies and children, introduced by Professor Robert Winston. The programmes explored levels of confidence amongst these small children, and in one of the programmes the children took part in a simple test to measure their levels of self-esteem. This involved completing a puzzle with an error built in so that the puzzle was in fact impossible to complete. We saw how the children dealt with this and most revealingly, how highly or otherwise the children rated themselves (in terms of two, four or six stars) after completing the test. How they approached the test varied; some gave up quite quickly, some sought almost constant approval for their handling of the task, and others doggedly stuck to the test even when it was obvious that it could not be completed.

All of the children were eventually rescued by the facilitator who gave them the right piece to complete the puzzle. How these children rated their efforts was not necessarily as one might have expected. The child seeking constant approval scored herself low on her efforts. Only one child, the hitherto shyest of the group, when offered a choice of three strips of paper, one containing two stars, one four stars and the last six stars, to signify his view of his efforts picked up all of them. Winston observed that the children with high self-esteem had parents with a high locus of control they felt that they were in charge of their lives and destiny.

Watching this programme, I was reminded of some of the discussions I have been listening to amongst dentists within the NHS when discussing the likely shape of the new PCT contracts post -March 2005, which are currently being determined around the country. Many of these conversations have centred around the key question of 'What should we do?' I have been asked for my opinion on the relative merits of different options and many practitioners are trying to determine the right road for them to take at the moment. The state of change and almost constant uncertainty may well be having an effect on the self-esteem of the profession.
'Wait and see' is still an option for many, but in my view, will not address the heart of the issue. What I am not suggesting is that practitioners and practices should make hasty decisions about their futures. What I do believe is that they should have a yardstick by which to measure the proposed changes.

That yardstick however, will not be given to them by anyone else. The only benchmark that is going to work is one developed by the practice or practitioner themselves. If the practice has a clear idea of what it is trying to achieve, in clinical and business terms, it will be easier to work out how far any new offering from a PCT will go to help meet what the practice is trying to achieve? However, these aspirations must be set out in meaningful and measurable ways and not in vague and woolly terms. The practice with clear measurable objectives has a compass to steer its way through sometimes turbulent seas of change, whereas the practice with none can only hope that what they are doing is the 'right' thing.

Asking other people for their advice may also not provide the quick answer to the question of practice direction. Alice, in Lewis Carroll's 'Through the Looking Glass', famously asked the Cheshire Cat which road she should take. The cat's answer said that it depended on where she wanted to go, which was sound advice and unassailable logic, if uncomfortable listening. No-one can advise on the best route for the practice until the practitioner has decided on the destination.

The real challenge for many practices is to make these changes measurable by deciding what they want from their own future and therefore provide the measure against which they can determine how appropriate or inappropriate a deal the proposed changes represent. It is only in this way that practitioners can make confident decisions about their own futures as professionals, and maintain a high level of self-esteem and confidence not just for themselves, but also for all stakeholders in their practice.

Fiona Stuart-Wilson, Associate Editor fiona@umdprofessional.co.uk doi:10.1038/sj.bdj.4810978 